\title{
Domesticity, Homosociality, and Male Power in Superhero Comics of the 1950s
}

\author{
Mark Best
}

In any examination of comics of the 1950s, Fredric Wertham and Seduction of the Innocent will inevitably come up, and any discussion of the superhero genre at the time, and its representation of masculinity, must mention Wertham's most infamous and oft-quoted assertion that Batman and Robin represent a homosexual fantasy. Wertham did correctly identify the possibility of a queer reading of the superhero, albeit as an example of what was wrong with the comics. His attitude indicates the important function of homosexuality in the fifties discourse of heterosexual masculinity to negatively define "normative" masculinity: the mature, responsible, white, heterosexual middle-class professional so strongly associated with the decade. While hardly a true or universal norm, this image of American manhood served as a locus for the popular expression both of "proper" American masculinity and of anxieties that arose from the dominant domestic ideology of the 1950s and its assigned roles of female homemaker, wife, and mother and male breadwinner, husband, and father.

Among his examples of signs of homosexuality in Batman and Robin comics, Wertham describes one quality that is less a sign and more an impression of a shared attitude: "The feeling is conveyed that we men must stick together because there are so many villainous creatures who have to be exterminated" (190). Focus-

Mark Best is a Visiting Lecturer in English at the University of Pittsburgh, teaching courses on film and popular culture. He received a Ph.D. in Comparative Literature from Indiana University in 2002, and is currently revising his dissertation, on masculinity and the superhero genre in the post-war era, for publication, as well as working on other projects related to comics and popular culture.

Iowa Journal of Cultural Studies 6 (Spring 2005)

Copyright (1) 2005 by The University of Iowa 
ing primarily on DC Comics' Superman and Batman, this essay argues that the homosociality Wertham zeroes in on functions equally, if not more so, within fifties superhero comics to represent and reinforce the genre's fantasy of male power and freedom vis-à-vis the confines of normative American masculinity. This homosociality took two dominant forms: the representation of women as threatening male power and freedom, especially via marriage and domesticity (most profoundly expressed in the potential revelation of the secret identity), and male camaraderie and shared knowledge as a means of containing these feminine, emasculating threats. Simultaneously, the genre used the innovation of the "superhero family" to satisfy the need for conformity to the heterosexual status quo and contain the threat of homosociality as a potential sign of homosexuality, while further expressing anxieties arising from the domestic ideology. Nonetheless, the possibility of the homosexual critique, calling the superhero's manhood into question, demonstrates the conflicted and precarious nature of the discourse of heterosexual masculinity in the 1950 s, especially as seen through the distorting lens of the hyperbolic male fantasy represented by the superhero.

\section{The Super Threat of Marriage and Domesticity}

The 1953 story "Captain Marvel's Wedding” is introduced to the reader by the cover image of a nervous, sweating Captain Marvel standing at the altar with a lovely bride. The same image is repeated on the story's first page, but with greater emphasis on Captain Marvel's nervousness and reluctance at the prospect of marriage. Instead of the expected "I do," the superhero can only stammer in four small word balloons "Ahem!" "Er . . . ulp!" "Koff!" and "Gulp!" "What's this?" the narrative text asks, and emphasizes the unlikelihood of the situation: "Captain Marvel a bridegroom? How did the World's Mightiest Mortal ever get into this situation? Let's find out!" (75). The same scene is repeated a third time at the end of the story, but by now the reader knows the truth about the bride-to-be. "The big boob had better say 'I do' quick, or ... .' the bride thinks, when suddenly, in the next panel, she is transformed into a hideous witch, and Captain Marvel grabs her arm in a crushing grip. “. . . It's midnight! I wanted everybody to see this, Theo!" Captain Marvel says. "Now they will all know you're really a witch and won't think I'm a heel for not marrying you!" (83).

The reader has seen how "Theo Hagge," a pretty receptionist, has manipulated Captain Marvel into marrying her after he rescues her from a dangerous witch who has been harassing the broom factory where she works. Acting as her bodyguard, Captain Marvel quickly becomes the object of public speculation as to his intentions. He discovers that Theo and Mr. Morris, the boss of his alter ego Billy Batson at radio and television station WHIZ, have already planned his and Theo's wedding, to be nationally televised. The news makes Captain Marvel weep, and a few panels later, as he walks down the street in a daze, he says, "Holey moley! I'm going to be married! Mr. Morris and Theo have everything arranged-I can't back out now or I'd be the World's Mightiest Heel!" (81). The narrative is blunt in its assessment of marriage for the superhero, whom C. C. Beck draws throughout the story as 
shaking, sweating, weeping, slumping, confused, shocked, and with his head spinning at the prospect. Captain Marvel has been trapped, "never suspecting that he's sinking deeper and deeper into an ugly quagmire that will ruin him!" (80).

The consequences of marriage in this story resonate with the fifties' discourse of Momism. Philip Wylie's best-selling Generation of Vipers, first published in 1942, helped to establish the rhetoric of Momism that would later attach to popular expressions of male anxiety arising from the domestic ideology. Beautiful Theo recalls Wylie's "Cinderella," the idle young woman who expects to achieve wealth and social control through marriage, at the expense of male freedom and power, and whom Wylie claimed was becoming the dominant model of American womanhood. Like Theo's transformation into a witch at midnight, Cinderella eventually turns into "Mom," whom Wylie explicitly characterizes as a "witch," among other things (215-16). ${ }^{1}$

For Wylie, whose 1930 science fiction novel Gladiator was a key inspiration for Jerry Siegel and Joe Shuster's creation of Superman, the danger of Momism was not just to the individual would-be husband, but also to America as a whole, whose moral fiber was dependent upon American manhood. Indeed, from the perspective of fifties' masculinity, perhaps the most striking moment of "Captain Marvel's Wedding" is Theo's fantasy of the hero's future. Theo imagines Captain Marvel out of costume, washing dishes and wearing an apron ("Holey moley!" he sadly intones):

Ha ha ha! I've succeeded! Once I'm married to Captain Marvel I'll be safe! Even if he finds out I'm a witch, a husband can't testify against a wife! I'll make him buy a regular suit, and I'll make him get a job! I'll take all his pay, and I'll make him stay home every night...

In the next panel Theo reveals the rest of her plan: “... while I go about building up the witch business again! A world without Captain Marvel will be a world safe for witches!" (81). Theo's plan to render Captain Marvel powerless through marriage is cast specifically in the terms of the domestic ideology's masculine norm. In other words, the male breadwinner role is inherently emasculating, and male powerlessness against the wife's control is assumed to be a part of marriage in this parody. Furthermore, the good, free, super-powered male hero is the only obstacle to the evil, super-powered female witch's freedom and desire to "build up the witch business." Thus, male freedom outside marriage is presented as directly counter to female freedom and power obtained through marriage, and the latter is evil.

Another equally over-determined story about marriage's dangers for the superhero appeared from 27 August to 10 November 1945 in the Superman daily newspaper strip, written by Alvin Schwartz. This story focuses on Superman's proposal to Lois Lane and the humorous chaos that ensues. At the story's end, after Superman abandons Lois at the altar, Clark Kent explains to Lois that Superman's motives were to make the world think Lois and Superman despise each other, in order to protect Lois from those who might try to attack Superman through her-the oftrepeated narrative explanation for why superheroes cannot marry. However, this narrative reason is also juxtaposed with the ideological reason, that marriage is an emasculating threat to male power and freedom. The view is expressed by Gaunt, a criminal who wants to exploit Superman's marriage in just this way. When Gaunt's 
partner Beazly objects to Superman's marriage because it will ensure happiness for the superhero, Gaunt replies:

Gaunt: Happiness? Ha! He who shares his life with a woman becomes a sniveling toady! His keen male instincts vanish! He becomes fat and foolish! If Superman marries, he won't be half the worry he is now!

Beazly: So you hate women! So what! There's plenty happily married guys! Gimme a practical reason for helping Superman marry, and I'll listen, but-

Gaunt: Practical, eh? Don't you realize that marriage provides the invulnerable Superman with an Achilles' heel? We can't harm him, but he's bound to lay off us rather than have his wife become a target! (11 Sept. 1945)

Later in the story, Gaunt repeats the consequences of marriage for masculinity: "We must allow sufficient time for marriage to reduce Superman to the fat, flaccid and comfortable state enjoyed by those males who forsake the independence of bachelorhood" (8 Oct. 1945). While tying women to marriage and to the threat of emasculation may make Gaunt a misogynist, as Beazly points out, in the context of the superhero comics' hyperbolic fantasy of male freedom he is also correct.

Like Captain Marvel, Superman escapes marriage and the consequent loss of power. However, just the prospect of marriage-even when initiated by the superhero himself-results in heavily gendered chaos. When Clark Kent refuses to be Superman's best man, the women of Metropolis take to the streets to protest him as "the enemy of romance" (21 Sept. 1945). Later, after Superman jilts Lois, the same women approve because he is "a symbol, a public figure, and, in a sense, he should belong to all of us!" (31 Oct. 1945). A riot breaks out when Superman and Lois go shopping together. Circumstances force Superman to wash all the dirty diapers in Metropolis. Not surprisingly, their engagement also threatens Superman's secret identity when Lois insists that Clark be his best man. Their engagement is further punctuated by Lois's comments suggesting the bleak future Gaunt has already predicted for Superman:

Some fiancé you are! Never anywhere on time! Always running off and leaving me! Always changing any plans we make! I won't stand for it! (18 Oct. 1945)

That man! Busy with everybody else's troubles and leaving me, his own fiancée, stranded. Well —only two days left until the wedding, then just watch Mrs. Superman put her foot down!! (19 Oct. 1945)

Marriage to Superman means power and social mobility for Lois, and Lois fantasizes: "Yes, Mrs. Superman . . . How de do, Mrs. Superman ... Do come for tea at the White House, Mrs. Superman. The President will be so delighted." For Superman it is akin to the ultimate loss of power: "This is the feeling a condemned man must have!" (20 Oct. 1945).

While the critique of the domestic ideology's model of proper gender roles in 
marriage was rarely as explicit as in these stories, it was certainly implicit in the genre's representation of fantasies of male freedom. In this regard, the genre was closely allied ideologically with a similar espousal of male freedom from marriage and the expectations of the domestic ideology. Hugh Hefner's Playboy philosophy, found in the pages of Playboy magazine, valorized bachelorhood and espoused noncommittal heterosexual relationships. Playboy first appeared in December 1953, a mere month after "Captain Marvel's Wedding," and both of them, in the spirit of Wylie a decade earlier, mistrusted those women who would economically (and, in the case of Playboy, sexually) enslave American men. What was new in the model of masculinity presented in Playboy was a hedonistic "fun morality," in keeping with fifties' consumerism and leisure culture but constructed in opposition to the domestic ideology (Ehrenreich 45-46).

The playboy disguise worn by Batman's alter ego Bruce Wayne and a host of other earlier heroes' secret identities predates Hugh Hefner's image of the playboy by almost 15 years, and signifies at best indolence and leisure, at worst buffoonery, in contrast to the super-powered man of action. In many superhero comics, while the playboy is not a desirable model of masculinity, the bachelor's irresponsibility and immaturity_potential signs of homosexuality vis-à-vis the domestic ideology's construction of normative masculinity-are rendered non-threatening by the inability to take him seriously. The playboy identity also aided in narratively explaining for readers the superhero status of Batman and others like him-i.e., the possession of phenomenal wealth and leisure time necessary to be a superhero without superpowers. Playboy made bachelorhood more socially acceptable-or at least desirable - through its celebration of male-oriented leisure goods and pleasure in one's vocation, lifestyle traits ostensibly inaccessible to the man working to support a wife and family. Likewise, being a superhero in the fifties was fun, signified not only by the freedom of crime-fighting, but also by the hero's male-oriented leisure goods, such as Batman's Batmobile, Batplane, Batboat, etc. Bruce Wayne may have played the buffoon, but Batman embodied the consumerist aspects of the new fifties' playboy. ${ }^{2}$

Not surprisingly, however, the crucial, defining element of Hefner's version of the playboy is missing from the superhero genre: sex. While "irresponsible" and "immature," the Playboy philosophy made this non-conformist model of masculinity both safe and desirable by placing the blatant expression of male heterosexuality at its center (Ehrenreich 51). Several reasons exist for the absence of the overt representation of sexuality in fifties superhero comics, not least of which was the presumed juvenile audience and the institution of the comics code in 1954-although Fredric Wertham and others argued that sex was, in fact, plentiful in the comics and harmful to juvenile readers. Also significant was the structural problem of avoiding significant transformations of the protagonist; the superhero could not marry, reproduce, or do anything else that might permanently change him-he could not do anything that would consume him and thus move him closer to death or obsolescence (Eco 114-15). Furthermore, if the "proper" place for sexuality and heterosexual desire was within expressions of heterosexual romance or the institution of marriage, then the threat posed to male freedom by marriage and domestic 
entanglement rendered the representation of heterosexuality via marriage and romance as likewise untenable.

Consequently, heterosexual desire in superhero comics took several different forms. Most obvious, perhaps, was the constant emphasis on women's desire for the superhero (e.g., Lois Lane), as well as the utilization of certain erotic substitutes. Superman was constantly rescuing Lois from danger, and the danger often resulted from the woman's scheming pursuit of the hero's love. However, Lois's desire was not limited to love for Superman: Lois (and any other woman who pursued romance with a superhero) also sought to discover Superman's secret identity. For Lois, this discovery meant the scoop of a lifetime, which would advance her career as a reporter while ruining Superman's career as a crime-fighter. The pursuit and capture of or by female criminals also functioned as such an erotic substitute. In “The Jungle Cat-Queen” (1954), for example, Batman's antagonist and occasional paramour the Catwoman leads the Dynamic Duo on a jungle chase. She forces them to strip down to just their masks and "jungle clothing"-_Soon, animal skins transform the detective duo into primitive men of the jungle!" Catwoman adds, "And taking off your masks will be the climax of my chase!" (101).

Wertham locates villainesses among the elements of the genre that frighten young boys and fix any homosexual tendencies they might have:

In these stories there are practically no decent, attractive, successful women. A typical female is the Catwoman, who is vicious and uses a whip. The atmosphere is homosexual and anti-feminine. If the girl is good-looking she is undoubtedly the villainess. If she is after Bruce Wayne, she will have no chance against Dick. (191)

A more reasonable interpretation of such eroticized villainesses, however, is that they contribute to the genre's presentation of domesticity as dangerous to male freedom. As in Classic Hollywood cinema specifically and American mythology and literature in general, the desirable, sexualized woman, who signifies male freedom through her association with spectacle, crime, and desire, is set in contrast to the undesirable wife, signifying responsibility, conformity, and entanglement (Ray 59-61). Thus, in the superhero genre any threat that the villainess might pose to male power or conformity to the social order, through her eroticisation or its displacement onto criminality, is contained via her identification as "bad"- - as a villainess to be captured and literally contained in jail. In other words, the genre allows the reader to have it both ways, simultaneously critiquing and reinforcing the domestic ideology even as it presents a fantasy of freedom from the perceived constraints of normative masculinity.

Catwoman always fails, of course, as do any other women who try to entrap the superhero, whether through marriage or crime. Regardless of whether the female pursuer is designated by the narrative as "good" or "bad," she is a dire threat to the superhero. Thus, a constant expression of male power in the genre is the woman's defeat and sometimes humiliation-teaching her a lesson-and the recuperation of male supremacy over would-be female empowerment. 


\section{Male Homosociality and the Secret Identity}

As Catwoman's threat-that unmasking the heroes is the climax of the chasesuggests, the erotic is most significantly displaced in the superhero comics onto the discovery of the superhero's secret identity. This discovery is the potential climax not only of Catwoman's criminal pursuit of Batman and Robin, but also of Lois's pursuit of Superman, whether to achieve marital or career goals. Consequently, the world of the 1950s superhero is a distinctly male world into which women can only intrude. At best, women are a nuisance; at worst, a threat not just to male freedom, represented primarily by crime-fighting, but to the most important signifier of male power in the genre, the secret identity. Just as threats to the superhero took the form of either the literal loss of power or the loss of the secret identity, so the mere possession of the secret of the secret identity signified the power of the superhero. Thus, in "The Batwoman" (1956), Batwoman, alias Kathy Kane, a wealthy young heiress and adventuress, poses a double threat to Batman and Robin. She not only repeatedly beats them in their crime-fighting efforts and saves Batman, but also issues a more dire threat: "Batman, I give you fair warning-if you ever should penetrate $m y$ secret, you'll be automatically revealing your own identity!' (72). Batman and Robin seek to end her crime-fighting career for her own good, to protect her and teach her that crime-fighting is not a proper career choice for a woman. Of course, Batman and Robin do succeed in discovering her secret identity while preserving their own, and Batwoman promises to leave her life of crime-fighting, at least temporarily. Thus, even a superheroine, embodying the same values as the male hero, also represents a threat to male power in the genre, and that power is maintained through the gendered possession of knowledge of secret identities.

Male homosociality in the superhero genre is represented in the form of male companionship and camaraderie in the career of crime-fighting, but cemented through the currency of the secret identity. The relationship between the superhero and the boy sidekick, for example, is usually presented as stronger than any heterosexual relationship-the fact of which so disturbed Fredric Wertham. This relationship, epitomized by Batman and Robin, of course, was echoed in such partnerships as Captain America and Bucky, Green Arrow and Speedy, the Human Torch and Torchy, etc. Although the elder hero fills something of a father role, as in Batman's training of the young Dick Grayson to become Robin, the hero and his partner tend to be best friends and equals rather than hierarchically bound according to familial ties. The strength of this bond is repeatedly demonstrated in fifties comics by the willingness of each to risk his life to protect the other. The boy sidekick also is typically the only person close enough to the hero to share knowledge of the hero's deepest secret, the secret identity, although occasionally other superheroes and adult males are also permitted access to the secret identity, such as Alfred, Batman and Robin's butler (who also functions as a sign of Bruce Wayne's wealth). The potency of this homosocial bond is perhaps most forcefully expressed in two stories from the early 1950s that team Superman and Batman together.

In Batman and Superman's first meeting, "The Mightiest Team in the World!" in 1952, an apparent love triangle between Superman, Batman, and Lois Lane func- 
tions to reinforce the genre's structures of male power. On the cover, Lois Lane stands on the roof of a burning building. Superman flies towards her from one side, saying "Lois in danger! This is a job for Superman!" while Batman swings towards her from the opposite direction, saying, "No, this is a job for Batman!" On the comic book's splash page, as Lois stands with her foot stuck in a railroad track, Superman stops an approaching locomotive with one hand while Batman swings past him to the rescue. Both images depict events that never occur in the story itself, while suggesting to the reader that the focus of this first, historic meeting will be a rivalry over Lois's affections. Such is not the case-indeed, quite the reverse.

Coincidentally forced to share a cabin on a cruise ship, Clark Kent and Bruce Wayne discover each other's secret identity as they struggle to change into their costumes in the dark. Superman extinguishes a fire on the dock while Batman rescues Lois, much to her surprise. Superman and Batman immediately begin to collaborate on capturing the story's criminal while promising to keep their alter egos secret. However, this newfound bond between the two heroes is threatened when circumstances necessitate Batman, Superman, Bruce Wayne, and Clark Kent to all be traveling aboard the same ship, joined by Lois Lane. The complexity of maintaining the simultaneous presence of all four identities makes the risk of discovery by Lois that much greater. Clark Kent pretends to be seasick, and Bruce Wayne must care for him in their cabin, the secret identities masquerading as inadequate masculinities to distinguish them from and preserve the superior masculinity of the superhero identities. To keep Lois Lane from obstructing their crime-fighting, Superman and Batman decide to feign rivalry over her. Superman says, "Say-I just thought of a way to keep Lois out of my hair! If you could pay attention to hermake her think you're falling for her-and I pretend to be jealous, she'd be too occupied for amateur detective work!" (7). Although Lois discovers their scheme and plays along, they ultimately capture the criminal and get the better of her.

The homosocial bond that the story is trying to emphasize is visually reinforced repeatedly throughout the story. At the beginning, the dual identities of both heroes are shown in parallel: Batman and Robin turn a criminal over to police then change out of their costumes, followed by two panels depicting Superman concluding a mission then changing back into Clark Kent (2). The reader sees them changing into or out of their costumes together in the privacy of their shared cabin $(4,7)$. Then, at one point in the performance of their rivalry over Lois, two panels depict Lois standing between the two superheroes (as on the cover) (8); however, at the end of their investigation, Lois stands to one side while the heroes leave the ship together, immediately followed by an almost identical tableau of Lois confronting Clark and Bruce, who are still on board (11).

At the story's conclusion, Batman disguises himself as Clark Kent in order to allay Lois's suspicions, and the final two panels provide the most emphatic visual expression of this bond: Superman holds Batman's mask while Batman removes his Clark Kent disguise to reveal his costume underneath, and they express their concern over which of them Lois really prefers. This concern seems hardly due to jealousy. Earlier in the story Superman seems quite willing to concede to "the better man" (9). Instead, this rivalry suggests a greater concern about which superhero 
she will plague with her attention in the future. The threat of Lois's affection is humorously resolved in the last panel, when the two heroes see Lois walking away on Robin's arm: "Isn't he the cutest little chap?" (12).

"The Mightiest Team in the World" neatly summarizes the superhero genre's representation of male homosocial desire in the fifties, signified by the sharing of the secret identity and the management of female desire and power. The bond of rivalry over the female lover is not only stronger than either man's desire for the woman, but that rivalry is also performed solely to preserve the homosociality signified by the rivalry. The second team-up of Superman and Batman, "BatmanDouble for Superman!" published two years later, represents male homosociality in an almost identical manner, including repeated visual images of the two heroes together with their dual identities simultaneously revealed. The first panel of the story quotes the heroes' mutual discovery in the dark cabin, to remind the reader of that first meeting. However, although Lois Lane poses the same threat to the heroes' secret identities, male rivalry is replaced by the exchange of another signifier of male power, the heroes' superpowers themselves. Superman loses his superpowers and must become Batman, while Batman gains superpowers and must pretend to be Superman. Much of the story focuses on the heroes once again outwitting Lois's attempts to discover their secret identities. After she witnesses Superman changing into Clark Kent, they proceed to confuse her with the ruse that Bruce Wayne is actually Superman. The emasculating threat represented by Lois is overdetermined to the point that Lois attempts to cut Bruce Wayne's hair (in order to disprove that he is Superman and thereby confirm her suspicion that Clark Kent is) while the two of them look at a painting of Samson and Delilah (7). Similarly, Lois unmasks an unconscious "Batman" only to find Clark Kent underneath, already rendered powerless by kryptonite (11).

These structures of male power in the genre were firmly in place throughout the fifties. In World's Finest Comics, which specifically emphasized the partnership of these two superheroes, the representation of male homosociality as the expression and basis of male power, as well as the means of its preservation, was not surprisingly the dominant trope. Indeed, in a 1958 World's_Finest story, "The Origin of the Superman-Batman Team," instead of a woman or even the secret identity functioning as the currency of homosociality, homosociality itself becomes the object of male rivalry. The story offers a new and entirely different version of the two heroes' first encounter. Instead of discovering each other changing costumes in the dark and tricking Lois Lane with feigned romance, Superman and Batman "first" team up in a spectacle featuring helicopters, robots, and kryptonite. Batman and Robin reminisce about their first partnership with Superman, in the context of a frame story in which Superman rejects their help in favor of a new superhero named Powerman. The retelling occurs as the Dynamic Duo mopes over being left out: "We didn't have to watch from a distance in our first adventure with Superman!" Batman says, frowning (126). When Powerman bluntly tells them, "I' $m$ all the help Superman needs!" (127), Robin confronts Superman, "You're rejecting your friends for this Powerman, whoever he is!" (128).

The entire narrative is structured around the anxiety Batman and Robin feel 
when the homosocial bonds of the superheroes are threatened by the presence of an ostensibly superior hero. Even Powerman's name suggests he might be a better partner for Superman, more in line with the model of male power that Superman represents, and so better suited to the task of dangerous crime-fighting. As Robin notes, they do not even know Powerman's secret identity. The spectacle of the heroes in action and Batman's use of his detecting skills are secondary to the narrative emphasis on the emotional crisis of Superman's apparent betrayal, and Superman's rejection of Batman and Robin threatens to render them narratively powerless. At the story's end, after Batman and Robin do help Superman while Powerman does not, Superman explains that Powerman is simply a robot decoy, built by him to keep Batman and Robin from danger. As Superman strips the superhero costume from the robot's body in the final panel, Batman and Robin grin with relief. "We might have known you'd never replace us with a real new partner!" Batman says (130). "The Origin of the Superman-Batman Team" further foregrounds the genre's privileging of male camaraderie and partnerships through the absence of women and secret identities from the narrative. Bruce Wayne and Dick Grayson appear in only two panels of the story, while Clark Kent is entirely absent. The only thing that is at stake here is the power implicit within the structures of male homosociality as they are played out in the genre.

\section{Superhero Families}

While the superhero genre worked hard to construct signifiers of male power and freedom from the conformist constraints of marriage, domesticity, and other entanglements represented by women, the genre was not entirely the biting critique of the domestic ideology that these examples might suggest. One way the genre attempted to contain any "subversive" potential, including the possibility of homosexual readings of the comics, was through the narrative device of the "superhero family." The superhero family was an expansion of the cast of the primary superhero comics-i.e., Superman and Batman-to include new superheroes and other characters or foreground supporting characters. Thus, characters such as Batwoman (1956), Bat-Girl (1961), and Superman's cousin Supergirl (1959) were introduced. Clark Kent's editor Perry White and Batman's police contact Commissioner Gordon enjoyed more prominent narrative roles, functioning as paternal or avuncular figures. Superman regulars Jimmy Olsen and Lois Lane were given their own comic books in 1954 and 1958 respectively. At the head of each "family" of characters was the benevolent authority of Superman and Batman, the relationships of niece, cousin or "pal" avoiding the narrative and ideological messiness of marriage and reproduction.

The superhero families introduced in the mid-to-late 1950s were in part inspired by Fawcett Comics "Marvel Family" of the 1940s and early 1950s. Captain Marvel was joined by his sister Mary Marvel and number-one-fan Captain Marvel, Jr., and other recurrent cast members. In addition to expanding the number of comic books based on the popular original character, one function of the Marvel Family was to increase these comics' potential for humor and gentle parody (as well as not-so- 
gentle, as in the case of "Captain Marvel's Wedding"), qualities that, along with the often humorous drawing style, primarily by C. C. Beck, set the Marvels apart from supposedly more serious superheroes.

In contrast to the Marvel family, however, the Batman and Superman families were modeled more after the familial relations of the nuclear family and the gender expectations of the domestic ideology. The advantages for the genre were numerous. As with the Marvels, most obvious was the exponential increase of narrative possibilities. An increased number of supporting characters meant an overall enrichment of the genre's potential for character development and interaction. However, familial relations (or surrogate versions thereof) could also present new narrative expectations for creators to play with. For example, Superman functioned as a father figure of sorts for Kara, alias Supergirl, an actual blood relative from Krypton, while she learned about life on Earth and how to use her powers for truth, justice, and the American way. The convention of the super family extended across time as well, allowing Superman himself to occupy the role of son as Superboy, with young Clark Kent involved in middle American adventures with his parents and friends in Smallville, stories that mirrored the narrative and ideological structures of the adult Superman. ${ }^{3}$

Ersatz family members could easily be introduced in one-shot appearances. Stories such as “Superman's Lost Brother!" (1953) or "Superboy's Sister” (1954) could thus explore then dismiss such family relationships, while relying on the reader's surprise and curiosity evoked by the titles to sell comic books. The introduction of recurrent pets in 1955-Ace the Bathound and the super-dog Krypto, each with his own "costume" to visually identify his ownership by a superhero-further replicated and exploited the familial structures of real-world American life. Supergirl had her own array of pets as well. Recurrent humorous versions of the principal heroes, such as the mischievous Bat-Mite and the insane Bizarro Superman, both introduced in 1959 (the latter introducing an extensively developed, parodic version of the Superman family), further reinforced the superiority of the hero at the family's head. ${ }^{4}$

Emphasizing supporting characters and giving them expanded narrative roles enabled the genre to explore narrative possibilities and cultural issues, as well as accompanying anxieties, to an extent that the more typical superhero stories did not allow. Unlike Clark Kent, who represented an undesirable version of adult masculinity, Jimmy Olsen embodied youthful immaturity and irresponsibility. Clark Kent was just a wimp and coward, but Jimmy might eventually grow up to be a fine specimen of normative male adulthood. Still, as Superman's pal he functioned as a different model of inadequate masculinity to play off the superior masculinity of Superman. Thus, Jimmy's adventures place him repeatedly in danger, requiring Superman's rescue. In addition to being captured by crooks, Jimmy might take on unusual occupations, travel to exotic locales, or undergo bizarre transformations, all ultimately due to his callow youth.

Lois Lane's own adventures clustered around predictable themes, also based on the genre's gender dynamics. She pursued Superman's affections and secret identity, of course, but with a female protagonist her stories could foreground specifically gendered aspects of American culture. Thus, Superman's Girl Friend Lois Lane utilized things like beauty, romance with men other than Superman, beauty 
contests, female vanity, fashion, and careerism as key narrative elements. For example, a Lois Lane story fairly typical of the early 1960s, "Lois Lane's Super-Brain!" depicts an amazing invention that increases the size of Lois's brain, making her the smartest woman in the world. However, Lois spends much of the narrative obsessing about the repulsiveness of her enlarged head and what Superman will think. In "Lois Lane, Hag!" (1961), Lois accidentally grows old, is publicly humiliated by Superman and her rival Lana Lang, wanders out of Metropolis, falls into a river, and drowns. Fortunately, she is only dreaming. In "The Fattest Girl in Metropolis" (1958), Lois is transformed into a fat woman by a growth ray, and the rest of the story involves fat jokes at her expense and her intense anxiety about Superman discovering her change. When she is about to regain her slim figure, Superman reveals that he himself was behind the change - a disguise that was, of course, "for her own good." Such stories reveal this particular comic book's penchant for combining bizarre humor with bleak misogyny.

Another major theme in Lois Lane and Jimmy Olsen's comics was the characters' acquisition of super powers and the hilarious and chaotic consequences. Such powers might also be accompanied by bizarre transformations, such as seen in "The Super-Brain of Jimmy Olsen" (1957), another story involving an enlarged head. A super-evolved Jimmy immediately discovers Superman's secret identity and forces him to perform a series of seemingly meaningless but spectacular tasks. Although Jimmy initially appears evil, the tasks save the world from future disaster, proving the super-powered Jimmy to be good. In the majority of such stories, however, the acquisition of super powers leads to even more trouble than usual, demanding an even more spectacular response from Superman to contain the threat - a threat often directed at Superman's own super-powered position of narrative and ideological privilege. Not surprisingly, such threats are also expressed in heavily gendered terms. Thus, the cover of Superman's Girl Friend Lois Lane 1 (Apr. 1958) depicts Lois dressed as a witch, flying past Superman on a broom. "Heehee!" she laughs, "Thanks to this witch's broomstick, now I can fly as fast as you, Superman!' Superman's response is aimed at the reader and articulates the obvious threat of a woman with super powers, in case the reader has missed the visual cues: "Great guns! Lois has supernatural powers-and they may prove mightier than mine!"

However, the most common theme of the Lois Lane stories was in keeping with those traits that defined her character and the emasculating threat she embodied in the fifties, even without super powers. The first comic book devoted solely to Lois Lane, Showcase 9 (Aug. 1957) sought to test the marketability of Lois as the main protagonist in three stories. "The Girl in Superman's Past” introduced Superboy's childhood sweetheart and equivalent of Lois Lane, Lana Lang, into the hero's adult world, a rival for Superman's affections. In “The New Lois Lane," Lois decides not to pursue Superman's secret identity just when Superman has developed an elaborate scheme to capture a criminal that depends upon Lois behaving in character. In "Mrs. Superman," Lois dreams that she has finally achieved marriage to Superman, and that domestic life with the Man of Steel is a nightmare-giving up her job to become a housewife (while her husband is constantly away, rescuing her pretty replacement), raising a super baby who can fly and smash walls, and learning that 
her husband is, in fact, Clark Kent, "the man no girl would want to marry!" The Lois Lane stories represent a constant cycle of conniving on the part of Lois to entrap the hero one way or another, via romance or knowledge, and to out-do Lana at the same time. The spectacle and entertainment value of such stories is based on the sheer elaborateness of the schemes, and the even more elaborate ends to which Superman must exercise his powers in order to avoid commitment to either woman and protect his secret identity. In these stories, crime-fighting was an afterthought, if present at all, replaced by gender conflict.

As "Mrs. Superman" demonstrates, even when Lois achieves her dreams, the result is most often presented as far from the romantic fantasy she had envisioned. In fact, Superman himself is responsible for twisting her dream into a nightmare, whispering suggestions into Lois's ear in order to wake her from a coma-she is so happy with her fantasy that she does not want to return to reality. Only the threat of adultery is sufficient to wake Lois. In this story, Superman is able to maintain his freedom even in Lois's fantasies, while Lois experiences only misery. Such domestic scenarios should have been impossible in the genre, because of the need to avoid the narrative exhaustion of the characters, thereby enabling the Superman stories to proceed infinitely. However, DC's writers found a way to begin exploring the infinite potential of marriage and domesticity implicit in the relationships of the Superman family. The "Imaginary Tale" or "Imaginary Story" did not just limit itself to the character dynamics established within "official" continuity, those stories that were not "imaginary" because they did not narratively consume the hero (cf. Eco 114-15). Thus, the reader could enjoy, say, the consequences of Lois marrying Superman's arch-rival Lex Luthor. The "Imaginary Stories" were not limited to romantic or domestic scenarios-both Superman and Lex Luthor became President of the United States in different stories, for example. However, the family dynamics implicit in the Superman comics had their most explicit articulation in these stories, which often drew extensively from the genre of romance comics for their visual and narrative style and impact. Thus, in “The Wife of Superman" (1961), Lois's lack of super powers (and subsequent need to keep her marriage to Superman a secret for her safety's sake) and Lana's schemes to win Superman are the causes of crisis in her marriage to Clark Kent. The reader sees glimpses of superhero spectacle on television, while Lois, wearing a headscarf and apron, performs household chores like sweeping and watching the super-powered kids, or paces angrily, frantically worrying about the state of her marriage. However, most of the comics' narrative takes the form of "talking heads," as Lois confronts Lana, or bursts into tears to be comforted by Clark, in the manner of romance comics of the time.

The story makes an interesting visual distinction between Clark Kent as a normative male and Superman as a man of action. In this fantasy scenario of Clark married to Lois, Clark is a typical American man, marriage functioning as the sign of his transformation from inadequacy to maturity. He appears as a loving husband and father, a responsible worker, and a helpful neighbor. Superman appears fully in the story only in the final four panels. He sits comforting Lois, but the issue they are discussing is Lois's lack of super powers. Their incompatibility is visually conveyed by the sudden shock of seeing Lois next to Superman in their suburban 
home, in contrast to all the preceding images of Lois with Clark. Lois should be happy with Clark-they look "right" together-but her "secret" marriage is a shambles. The story ends on a grim tone, their future happiness in question:

Lois: Sob! . . . I thought that every second of my marriage to Superman would be heavenly bliss! Not like this! - Is it silly and stupid of me to hate keeping our marriage a secret? When will I be able to shout to the whole world that the most wonderful man of all time is my husband! When??

Superman: I hope someday soon . . . perhaps ... if I succeed in giving you permanent super-powers so your life won't be in danger from my enemies!

Lois: Make it very soon, my darling, for the sake of our marriage ... our happiness ...make it soon ... soon!!! (19)

The desired effect is the emotional spectacle of the romance genre, albeit made strange through the emphasis on super powers. Furthermore, the narrative cliché of the superhero's family member as a potential Achilles' heel becomes the justification for explicitly dealing with anxieties arising from the domestic ideology, like bachelor Gaunt's "practical" application of his misogynistic perspective, as described earlier.

Like Lois's dream in Showcase 9, this story emphasizes the negative aspects of marriage to the superhero, and Lois's lack of super powers can easily be read as an unexpectedly explicit critique of the domestic ideology from a proto-feminist perspective. Her romantic expectations frustrated, Lois is trapped between an unhappy marriage and the loss of her career. When she attempts to get her job back from Perry White, in order to outmaneuver Lana and stop being a "household drudge," Perry tells her that "a woman's place is in the home! But if you want to work because the family needs money, don't worry! Clark will soon get a raise." At a rival newspaper, she is told "that here at the Chronicle we have a policy of never hiring married women! If your kids caught the measles, you'd quit us to take care of them at home! And you wouldn't be able to meet the deadlines! Sorry!" (17). Lois's frustration is not presented as inappropriate or counter to her proper maternal role-her children are immune from disease, after all. If only she had super powers, like her husband, she would not have these problems; she could have a career and a happy marriage and family. While Superman's Girl Friend Lois Lane typically presented the comics' best-known career woman as an invasive and annoying termagant, stories like this genuinely foregrounded the constraints of the American housewife within the domestic ideology, a critique which was increasingly present in the culture in general in the late fifties and early sixties, a decade after similar concerns about the dangers to masculinity posed by the domestic ideology were becoming current. In this regard, "The Wife of Superman" was remarkably in step with contemporary gender discourse in American culture.

In contrast, "Imaginary Stories" could also offer fantasies of romantic escapequite literally. In "Lana Lang's Romance with Superman III!" (1962), Lois does acquire super powers and the story opens with the happy couple dressed in matching red and blue costumes and capes. Lana visits them in Superman's Fortress of 
Solitude, which has become a super middle-class suburban home ("I gold-plated the cavern walls, and studded the gold with gems! I did all the mining and superdecorating myself! Glad you like it!" Lois says). Two tots romp in mini-Superman costumes. "Choke-if Superman had married me, they could have been ... mine!" Lana thinks (21). Lana maintains her composure despite the emotional agony of seeing her rival's happiness. Having nothing left to live for, Lana goes on to volunteer for a dangerous time travel experiment, which sends her into the future. She promptly meets a descendant of Superman. They fall in love, thanks to a technological device that indicates their perfect compatibility, and presumably will live happily ever after, although Lana's final thoughts confirm that the primary source of emotional spectacle in the story is not so much heterosexual desire but female homosocial rivalry: "How ironic that the man I love, and am going to marry, is the descendant of my former rival for the heart of Superman ... Lois Lane!" (27).

\section{Containing and Maintaining Homosexuality}

Superman might escape Lois or Lana's machinations aimed at marriage or penetrating his secrets, at least in non-imaginary stories, but he could not escape their presence. Thus, a primary function of Lois's structural designation as "Superman's girlfriend" was to signify a "proper" heterosexual relationship for the hero, even if his girlfriend was depicted as little more heterosexually desirable than his pal, Jimmy Olsen. The use of the would-be girlfriend to foreground the superhero fantasy as heterosexual was especially true with Batman and Robin, and one of the most obvious functions of the relationships of the superhero family was to ostensibly "balance" the male homosociality so essential to the genre, while simultaneously reinforcing the power it signified. Shortly after Fredric Wertham's accusations of homosexuality, the Batman comic books introduced Batwoman and, some years later, Bat-Girl to occupy the structural position of heterosexual love interest for each of the Dynamic Duo. Unlike Batman's own conniving version of Lois Lane, Vicki Vale, or the villainess Catwoman, as a superheroine and crime-fighter Batwoman was more Batman's equal and thus a more obvious heterosexual partner than, say, Lois Lane for Superman. Indeed, despite being a superheroine, her "proper" femininity and desirability are reinforced through her pin-up-like curves-after their first encounter, Batman promptly adds a life-size portrait of Batwoman to his collection of trophies - and her use of crime-fighting equipment in the forms of typical feminine accoutrements and commodities, such as a purse, lipstick, and powder puffs (cf. York, 108n2). Batman's superior power in the relationship was signified by his knowledge of Batwoman's secret identity, as noted earlier. Bat-Girl, alias Betty Kane, Kathy Kane's niece, provided the opportunity for a puppy love version, with Robin, of the adult heroes' "relationship."

The stories often feature "romantic" moments between the two hetero couples. The women are the more aggressive pursuers, and the duty of crime-fighting provides the narrative justification for the male heroes' reluctance, but the possibility of genuine heterosexual romance is present and occasionally emphasized. For example, in "The Menace of the Firefly" (1959), Kathy snubs Bruce to keep a date with 
Ted Carson, who is actually the villain. "Well . . . looks like Carson has suddenly made a big hit with Kathy! You jealous, Bruce?" Dick Grayson asks. "Perhaps-a little! After all, Kathy is attractive!” Bruce answers (n.pag.). "The Great ClayfaceJoker Feud" (1963) begins with a "pleasant interlude" between the two pairs of superheroes, the women out of costume as Batman and Robin pull up in the Batmobile. Kathy explicitly presents their heterosexual crime-fighting partnerships as the superhero equivalent of a date. "Robin, I can hardly wait to get into my BatGirl costume again! Won't it be terrific if we could go on a crime case together like the last time?" Betty sighs. "It sure would, Betty!" Robin sighs back (131). In "Prisoners of Three Worlds!" (1963), Batman and Batwoman face imminent death:

Batwoman: Hold me close! If I must die, I want it to be in your arms! Oh, Batman, you know I love you-dying wouldn't be so bad, if I knew you loved me, too . .

Batman: I-I do love you! I never wanted to admit it before ... Batwoman: Oh, Batman ...

In the final panel of this exchange, the two heroes kiss, without any narrative or spoken text to distract from the urgency of the moment (Fleisher 104-5).

Andy Medhurst, Will Brooker, and Chris York all argue convincingly that these characters are primarily a response to Wertham's accusations. However, they differ in their interpretation of the meaning and nature of that response. Medhurst argues that Batwoman and Bat-Girl represent the beginning of a homophobic backlash in the Batman comics, finding its fullest expression in the grim Batman of the 1980s. York argues that while the two female characters establish explicitly heterosexual structures and gender dynamics within the heroes' otherwise exclusively homosocial world, the Batman family contained the threat of homosexuality mainly via distraction. The new characters' visually and narratively shifted readers' attention away from Batman and Robin and thus away from the idea of homosexuality now attached to them.

In contrast Brooker argues that Batwoman and Bat-Girl simultaneously contain and maintain the potential for queer readings. Thus, for every assertion of romantic interest there is also a resistance to commitment, a representation of women as threats, and/or a rejection of romantic entanglement. In "The Menace of the Firefly," Bruce follows his admission that he is attracted to Kathy with "Bah! . . As if the Firefly isn't giving me enough trouble, now I've got a rival to worry about!" (n.pag.). In "The Great Clayface-Joker Feud," Betty immediately follows her sweet romantic exchange with Robin by getting right to the point: "Robin, I do wish I could see your face without your mask! I don't think it's fair that you and Batman know our secret identities while we don't know yours ..." Kathy is quick to add, "Well, how about that, Batman?" (131). Brooker points out other moments in the story that are can easily be read "as a mockery, rather than a celebration, of heterosexual courtship," such as Batwoman making fun of Bat-Girl's attempt to get Robin to embrace her, or Batman's reaction to Batwoman's offer to "soothe" Batman: "Gulp." In "Prisoners of Three Worlds," when faced with death, Batman can express his love; when that threat is removed, he faces the greater problem of getting 
out of it (152-53). Brooker acknowledges both that the genre has certain formal constraints and that women represent an emasculating threat in fifties' masculine discourse, but his primary interest is in the potential for queer readings:

...I would suggest that the trope of the "woman trap" in the Batwoman and Bat-Girl stories is played up through the gulps and dismayed glances to a point of excess, and that the preexisting Batman and Robin couple_-placed under threat by Betty and Kathy's advances_- provides extra support for a reading of these scenarios as "gay." (153)

The point here, however, is that either way-whether one accepts the genre's attempt at introducing "explicit" heterosexual structures through the superhero family, or interprets the superhero family as increasing the potential for gay readings (at least in the case of the Batman family)-the result is the same. Brooker himself evokes the fifties' bachelor discourse of the Playboy philosophy in his reference to the "woman trap" of the superheroine. Women are cast as threats to male freedom and power, to be escaped and/or controlled, and male homosocial power is restated and reinforced.

Eve Sedgwick notes that the relationship between male homosocial desire and structures of patriarchal power "may take the form of ideological homophobia, ideological homosexuality, or some highly conflicted but intensively structured combination of the two" (25). Superhero comic books in the fifties manifest the third form. Easily read as either homosexual empowerment or heterosexual power fantasy, with a homophobic cultural imperative to do so, this "highly conflicted" combination foregrounds the dependence of heterosexual masculinity, and by extension patriarchal power, on homosexuality to define and maintain itself in the fifties, its identity based on its ostensible non-identity as feminine or "not a man." The double negative here suggests the elusiveness of masculine identity, the fear that "real" masculinity has no substance and is absent. The hyperbolic nature of the superhero genre's fantasy of masculinity suggests an overcompensation, the weight of which makes the genre's ideological balancing act that much more precarious, as it tries to negotiate cultural encoded binaries of conformist and non-conformist, hetero and homo, male and female.

In contrast to the superhero comics that came before and followed after the kinds of stories examined here, the genre in the 1950s may seem at first glance to offer little by way of a cogent cultural critique. The superheroes battling the Axis and hardboiled hoods in the early 1940s and the popular post-war genres such as crime and horror that competed with superhero comics until the early 1950s appear obvious and focused in their cultural imperatives by comparison. Likewise, Marvel Comics' revision of the genre in the early 1960s foregrounded male anxieties, as heroes such as the Incredible Hulk were also monsters and Peter Parker's everyday struggles as a typical young man constantly impaired his ability to fight crime as Spider-Man. In 1965, two years after Batman gulped at Batwoman's advances, Marvel was celebrating the marriage of Reed Richards and Sue Storm of the Fantastic Four. Consequently, the Batman and Superman stories of the 1950s give the 
impression, not entirely incorrect, of being about very "non-superhero" things: bizarre transformations, visits to alien worlds, fights with colorful supervillains atop colorful giant props, and, as seen here, narrow escapes from plots to entrap the superhero in domestic entanglements or, worse, to reveal the hero's secret identity - all far removed from more "serious" articulations of the superhero genre dealing more seriously with social and cultural issues. However, as these stories reveal, the difference is not between present and absent but rather between explicit and implicit. Distorting the norms and expectations of the domestic ideology and the heavily gendered anxieties that arose from them and masking them with wacky hijinks, the hyperbolic vision of masculinity and gender relations offered by the superhero comics of the 1950 s demonstrates the superhero's status as a full participant in the popular discourse of and crisis in fifties' American manhood.

\section{Notes}

' For example: "the destroying mother," Medusa, harpy, "the woman in pants," Pandora, the Queen of Hell, Lilith, and "the black widow," among others.

${ }^{2}$ The performativity of the superhero and secret identities, and their relationship to one another vis-à-vis masculinity, as well as the superhero genre's wholehearted narrative participation in post-war leisure and consumer culture, are explored in depth in the larger work from which this essay is taken. Other criticism on the function of the secret identity and the superhero costume includes Eco (1979), Reynolds (1992), and Bongco (2000).

${ }^{3}$ Superboy, along with his human foster parents and other citizens of Smallville, first appeared as recurring characters in 1945, the earliest form of the Superman family outside the usual supporting cast, such as Lois, Jimmy, and Perry White.

${ }^{4}$ Bizarro first appeared in 1958 as a faulty duplicate of Superboy. The Bizarro version of the adult Superman that led to DC's creation of Bizarro World with its population of Superman-obsessed Bizarros, first appeared 1959.

\section{Works Cited}

Beck, C. C. "Captain Marvel's Wedding." Captain Marvel Adventures 150 (Nov. 1953). Fawcett Publications. Reprinted in Shazam! 3.17 (Mar.-Apr. 1975).

National Periodical Publications/DC Comics: 75-83.

Binder, Otto, Rubin Moreira, and Al Plastino. "The New Lois Lane" and "Mrs.

Superman.” Showcase 9 (Aug. 1957). National Periodicals Publications/DC Comics.

Binder, Otto, and Kurt Schaffenberger. "The Fattest Girl in Metropolis."

Superman's Girl Friend Lois Lane 5 (Dec. 1958). National Periodicals Publications/DC Comics.

Binder, Otto, Curt Swan, and Ray Burnley. "The Super-Brain of Jimmy Olsen." Superman's Pal, Jimmy Olsen 22 (Aug. 1957). National Periodicals Publications/DC Comics. 
Bongco, Mila. Reading Comics: Language, Culture, and the Concept of the Superhero in Comic Books. New York: Garland, 2000.

Brooker, Will. Batman Unmasked: Analysing a Cultural Icon. New York: Continuum, 2000.

Coleman, Jerry, and Al Plastino. "The Girl in Superman's Past." Showcase 9 (Aug. 1957). National Periodicals Publications/DC Comics.

Eco, Umberto. “The Myth of Superman.” 1962. Trans. Natalie Chilton. The Role of the Reader. Bloomington: Indiana UP, 1979. 107-24.

Ehrenreich, Barbara. The Hearts of Men: American Dreams and the flight from Commitment. Garden City, NY: Anchor Press/Doubleday, 1983.

Fleisher, Michael L. The Encyclopedia of Comic Book Heroes, Volume 1: Batman. New York: Macmillan, 1976.

Hamilton, Edmond, Sheldon Moldoff, and Charles Paris. "The Batwoman." Detective Comics 233 (July 1956). National Periodicals Publications/DC Comics. Rpt. in Batman in the Fifties. New York: DC Comics, 2002. 70-81. Hamilton, Edmond, Curt Swan, and John Fischetti. "The Mightiest Team in the World." Superman 76 (July-Aug. 1952). National Periodicals Publications/DC Comics.

“Lana Lang's Romance with Superman III." Superman's Girl Friend Lois Lane 36 (Oct. 1962). National Periodicals Publications/DC Comics. Rpt. as "Lana Lang's Romance with Superman VI" in Superman's Girl Friend Lois Lane 86 (Oct. 1968). National Periodicals Publications/DC Comics: 20-27.

“Lois Lane, Hag!” Superman's Girl Friend Lois Lane 40 (Apr. 1963). National Periodicals Publications/DC Comics.

“Lois Lane's Super Brain!” Superman's Girl Friend Lois Lane 27 (Aug. 1961).

National Periodicals Publications/DC Comics.

Medhurst, Andy. "Batman, Deviance and Camp." The Many Lives of the Batman. Ed. Roberta E. Pearson and William Uricchio. New York: Routledge, 1991. 14963.

“The Menace of the Firefly.” Batman 126 (Sept. 1959). National Comics Publications/DC Comics.

Mooney, Jim, Sheldon Moldoff, and Helen Vesik. "The Great Clayface-Joker

Feud." Batman 159 (Nov. 1963). National Periodicals Publications/DC Comics. Rpt. in The Greatest Joker Stories Ever Told. New York: DC Comics, 1988. $130-42$.

“Prisoners of Three Worlds!" Batman 153 (Feb. 1963). National Periodicals Publications/DC Comics.

Ray, Robert B. A Certain Tendency of the Hollywood Cinema, 1930-1938.

Princeton: Princeton UP, 1985.

Reynolds, Richard. Super Heroes: A Modern Mythology. Jackson, MS: UP of Mississippi, 1992.

Schwartz, Alvin, Curt Swan, and Stan Kaye. "Batman-Double for Superman!" World's Finest Comics 71 (July-Aug. 1954). National Periodicals Publications/ DC Comics.

Schwartz, Alvin. Superman. 27 Aug.-10 Nov. 1945. 
Sedgwick, Eve Kosofsky. Between Men: English Literature and Male Homosocial Desire. New York: Columbia UP, 1985.

Sprang, Dick, Stan Kaye, and Daniel Vozzo. "The Origin of the Superman-Batman Team.” World's Finest Comics 94 (June 1958). National Periodicals Publications/DC Comics. Rpt. in The Greatest Batman Stories Ever Told. New York: DC Comics, 1988. 119-30.

Sprang, Dick, Charles Paris, and Helen Vesik. “The Jungle Cat-Queen.” Detective Comics 211 (Sept. 1954). National Periodicals Publications/DC Comics. Reprinted in The Greatest Batman Stories Ever Told. New York: DC Comics, 1988. 97-108.

“Superboy’s Sister.” Superboy 34 (Oct. 1954). National Periodicals Publications/ DC Comics.

Superman's Girl Friend Lois Lane 1 (Apr. 1958). National Periodicals Publications/DC Comics.

“Superman's Lost Brother!" Superman 80 (Jan.-Feb. 1953). National Periodicals Publications/DC Comics.

Wertham, Fredric. Seduction of the Innocent. New York: Rinehart and Co., 1954.

“The Wife of Superman." Superman's Girl Friend Lois Lane 23 (Feb. 1961).

National Periodicals Publications/DC Comics. Rpt. in Superman's Girl Friend Lois Lane 96 (Sept.-Oct. 1968). National Periodicals Publications/DC Comics: 12-19.

Wylie, Philip. Generation of Vipers. 1942. New York: Holt, Rinehart and Winston, 1955.

York, Chris. "All in the Family: Homophobia and Batman Comics in the 1950s." International Journal of Comic Art 2.2 (2000): 100-110. 